Research Article

\title{
Hybrid nonlinear autoregressive neural network-Weibull statistical model applied to the supercritical extraction of lanolin from raw wool
}

\author{
Abel Valverde $^{1}$ (D) . Jesús Alvarez-Florez ${ }^{2} \cdot$ Francesc Recasens $^{1}$
}

Received: 2 April 2020 / Accepted: 31 August 2020 / Published online: 9 September 2020

(c) Springer Nature Switzerland AG 2020

\begin{abstract}
Supercritical extraction of lanolin from raw wool with modified $\mathrm{CO} 2$ ( $5 \%$ ethanol) at temperatures above the melting point of lanolin $\left(T=36-42^{\circ} \mathrm{C}\right)$ is difficult to model because of the multicomponent diffusion in the liquid layer. In this work, a neural network model is proposed based on the experiments previously published by our research group. Experimentally, the extraction of a $100-\mathrm{cm}^{3}$ packed bed of raw wool depends on five variables, i.e., temperature (60-80 $\left.{ }^{\circ} \mathrm{C}\right)$, pressure (120-200 bar), solvent mass flow rate (3-5 kg/h), wool packing density $\left(127-318 \mathrm{~kg} / \mathrm{m}^{3}\right)$, and time $(\sim 1 \mathrm{~h})$. A nonlinear autoregressive exogenous $(5,3,1)$ neural network was designed and trained with the experimental data augmented using an empirical Weibull statistical function. This correctly predicts the lanolin breakthrough at the extractor exit with only $\pm 0.42 \%$ error. The simple arithmetics of neural network allows a fast optimization with Genetic Algorithm to find optimum operation conditions for the extraction process.
\end{abstract}

Keywords High pressure extraction · Lanolin · Neural networks · Genetic algorithm · Weibull

\section{List of symbols}

a Mass transfer area, $1 / \mathrm{m}$

A Const. defined by Eq. (12), 1/s

AARD\% Absolute average of relative deviations,

Eq. (22)

b Weibull parameter

$\mathrm{Bi} \quad$ Biot number for mass

B Const Eq. (16), kg

bi NN bias neuron

c Const Eq. (17)

c' Const Eq. (14)

$\mathrm{Cg} \quad$ Fluid-phase concentration, $\mathrm{kg} / \mathrm{m} 3$

$\mathrm{C}_{\mathrm{L}} \quad$ Liquid-phase concentration, $\mathrm{kg} / \mathrm{m} 3$

$\mathrm{C}_{\mathrm{L} 0} \quad$ Initial lanolin liquid, $\mathrm{kg} / \mathrm{m} 3$

D Lanolin diffusivity, $\mathrm{m} 2 / \mathrm{s}$

K Henry equilibrium const.

$\mathrm{k}_{\mathrm{G}} \quad$ Fluid-side mass transfer coef, $\mathrm{m} / \mathrm{s}$

$Y(m, x) \quad$ Incomplete gamma function, Eq. (19)

Me, Mo Median and mode, $h$

$\begin{array}{ll}\mathrm{n} & \text { Time, } \mathrm{s} \\ \mathrm{P} & \text { Pressure, bar } \\ \mathrm{Q} & \text { Mass flowrate, } \mathrm{kg} / \mathrm{s} \\ \mathrm{R} & \text { Final radius, } \mathrm{m} \\ \mathrm{R}_{\mathrm{B}} & \text { Bed radius, } \mathrm{m} \\ \mathrm{r}_{0} & \text { Initial radius, } \mathrm{m} \\ \mathrm{r}_{\mathrm{v}} & \text { Mass transfer rate, } \mathrm{kg} / \mathrm{m}^{3} / \mathrm{s} \\ \mathrm{t} & \text { Time, } \mathrm{s} \\ \mathrm{T} & \text { Temperature, }{ }^{\circ} \mathrm{C} \\ \mathrm{u} & \text { Superficial velocity, } \mathrm{m} / \mathrm{s} \\ \mathrm{U} & \text { External input in } \mathrm{NN} \\ \mathrm{V} & \text { Total bed volume, } \mathrm{m}^{3} \\ \mathrm{~V}_{\mathrm{L}} & \text { Liquid volume, } \mathrm{m}^{3} \\ \mathrm{w}_{\mathrm{ij}} & \text { NN weights } \\ \mathrm{X} & \text { Variable Eq. (18) } \\ \mathrm{X} & \text { Extracted lanolin fraction } \\ \mathrm{Y} & \text { NN output } \\ \mathrm{z} & \text { Length coordinate, } \mathrm{m} \\ \mathrm{z}_{\mathrm{T}} & \text { Total bed length, } \mathrm{m}\end{array}$

$\triangle$ Abel Valverde, abel.valverde@upc.edu | ${ }^{1}$ Chemical Engineering Department, Universitat Politècnica de Catalunya, Diagonal 647, 08028 Barcelona, Spain. ${ }^{2}$ Internal Combustion Engines Laboratory, Universitat Politècnica de Catalunya, Diagonal 647, 08028 Barcelona, Spain.

SN Applied Sciences (2020) 2:1651 | https://doi.org/10.1007/s42452-020-03475-7 


$\begin{array}{ll}\text { Greek symbols } \\ a & \text { Weibull parameter } \\ \varepsilon & \text { Porosity } \\ \rho_{\mathrm{B}} & \text { Packing density, } \mathrm{kg} / \mathrm{m}^{3} \\ \rho_{\mathrm{L}} & \text { Lanoline density, } \mathrm{kg} / \mathrm{m}^{3} \\ \rho \mathrm{S} & \text { Solvent density, } \mathrm{kg} / \mathrm{m}^{3} \\ \rho_{\mathrm{w}} & \text { Wool density, } \mathrm{kg} / \mathrm{m}^{3} \\ \sigma^{2} & \text { Variance, } \mathrm{h}^{2} \\ \mu & \text { Mean, } \mathrm{h}\end{array}$

Acronyms

ANN Artificial neural network

LM Levenberg-Marquardt

SCFE Supercritical fluid extraction

NARXNET Non-linear autoregressive with external NN

\section{Introduction}

The early attempts to extract lanolin from raw wool using supercritical carbon dioxide date back to 1990s, and are due to King and coworkers [1], Koo et al. [2], and to New Zealand researchers [3]. In all cases, pure compressed $\mathrm{CO}_{2}$ was employed. The first experimental systematic study, published a few years later, is that due to Eychenne et al. [4]. In their work, $\mathrm{CO}_{2}$ modified with $5 \%$ ethanol was used under near-critical conditions; this allowed operation at lower pressure. Higher extraction yields were possible. Recently, we published an article dealing with the modeling of the extraction of solid lanolin from raw wool using modified $\mathrm{CO}_{2}$ [5]. At $30^{\circ} \mathrm{C}$, the lanolin is a solid (mp. 38-44 ${ }^{\circ} \mathrm{C}$ ) and the fluid is a liquid. For these conditions, extraction kinetics could be interpreted with the shrinking-core concept [5]. In this case, the pure solid lanolin covering the wool fibers is in direct contact with the fluid and is progressively dissolved by direct contact with the flowing solvent. In this model, two solid lanolin fractions are assumed to be located one over the other on the wool fiber, as suggested by the experimental results obtained in the fractionation process developed by Bayona et al. in a patent $[6,7]$, and chemical characterization of the fractions $[8,9]$.

The present work, based also on the same experiments [4], comprises wider ranges of temperature, pressure and other variables, as summarized on Table 1 . As can be seen, in all the extraction runs lanolin is extracted from a liquid into a near-critical fluid at temperatures above the melting point of lanolin, i.e., 60 to $80^{\circ} \mathrm{C}$. For these temperatures, the conservation equations for lanolin become complicated by the fact that a multicomponent liquid phase is present, involving additional mass transfer resistances compared with the extraction at temperatures below the lanolin melting point where lanolin is a pure solid. For
Table 1 Settings for lanolin extraction runs from raw wool [4]

\begin{tabular}{ll}
\hline Temperature, $T$ & $60,80^{\circ} \mathrm{C}$ \\
Pressure, $\mathrm{P}$ & $120,150,200 \mathrm{bar}$ \\
Solvent mass flow rate, Q & $3,4,5 \mathrm{~kg} / \mathrm{h}$ \\
Solvent passed & Up to $5 \mathrm{~kg}$ \\
Wool packing densities, $\rho_{B}$ & $127,159,227,318 \mathrm{~kg} / \mathrm{m}^{3}$ \\
\hline
\end{tabular}

*Extraction solvent composition: $95 \%$ wt. $\mathrm{CO}_{2}-5 \%$ ethanol; total extraction time $1 \mathrm{~h}$

temperatures above $30^{\circ} \mathrm{C}$, the lanolin diffusion equations from the liquid up to the liquid-fluid interface makes solution very difficult.

In [10], an exact analytical solution of the conservation equations with some simplifying assumptions was obtained. The corresponding theory is summarized below in the Conservation equations, paragraph 3.1. It is evident, however, that the conservation equations become very complex, because not only lanolin is extracted to the fluid, but also $\mathrm{CO}_{2}$ and ethanol are dissolved in the liquid phase, thus giving a very complicated situation to model.

On the other hand, artificial neural networks (ANNs) can be used to solve the conservation equations in cases where the physical model is either very complex, the solution algorithm is difficult, or it does not exist [11, 12].

In the present case, we are interested in the effects of the factors that influence the yield and rate of extraction of lanolin from wool. The main feature of ANNs is their ability to learn by reproducing the output from a given input by observation and minimization of the error providing an optimal set of weighting parameters. In the prediction process, no explicit law is assumed that relates output from input.

It will be apparent that our extraction runs can somehow be considered as a desorption process. As regards to a work on adsorption column operation, an early paper due to Bulsari and Palosaari $[13,14]$ dealing with system identification was very interesting to us. In our case, lanolin is not held on wool fibers by adsorption. Instead, dissolution of lanolin in the solvent depends on how far the fluid is from saturation, so the rate of dissolution depends on a mass transfer coefficient and a concentration gradient.

Our objective in this paper was to use neural network computing combined with the properties of the conservation equations for lanolin extraction from raw wool, as described below. To this end, experimental data about the variables that affect the extraction rate and yields are essential. In this sense, the systematic extraction study data [4] is most appropriate to try to model. In the following text, we first present the Experimental data available. Then, in the Theory section, after doing a deep statistical analysis of available data, we discuss the selection of the recurrent networks and the available tools in the literature, 
and present the details of the training data sets and test data sets. Finally, in the presentation of Results, we solve a few optimization problems relative to lanolin production.

\section{Experimental background}

The experimental study behind this work was published elsewhere by Eychenne et al. [4]; the reader should refer to it for details. Here, we report only a few significant features. A Separex 200 unit was used for the high-pressure extraction. This is shown on Fig. 1. A summary of the scope of the measurements, features of the extractor vessel and the wool stock used are given in Table 2.

\section{Theory}

\subsection{Conservation equations}

Consider a vertical bed of packed wool from which the lanolin deposited on the fibers is extracted by the flowing solvent. See item $E$, in Fig. 1. At $t=0$, a step input of lanolin-free solvent is introduced in the bed at $z=0$, while fluid saturated with lanolin is removed at the other end of the bed at $z=z_{T}$. If pressure drop is neglected, the solvent passes through the bed in plug flow at constant pressure and temperature. The rate of extraction depends on two factors: the solubility of lanolin in the solvent and a mass transfer coefficient. Two assumptions are made: (1) since the amount of lanolin on the wool is small, the bed void fraction, $\varepsilon$, is about constant and equal to that of packed wool; and (2) since the layer of liquid lanolin covering de fibers is very thin, the total mass transfer area, a, can be considered constant; therefore, the holdup of liquid in the bed, $\varepsilon_{\mathrm{L}}$, can be taken equal to its average value during the extraction process. With these assumptions, the balance equations for lanolin in the flowing fluid and in the liquid phase, respectively, are:

$\varepsilon \frac{\partial C_{g}}{\partial t}+u \frac{\partial C_{g}}{\partial z}=r_{v}$

$-\frac{\partial\left(V_{L} C_{L}\right)}{\partial t}=V k_{G} a\left(C_{g}^{*}-C_{g}\right)$

where $r_{v}$ is the volumetric mass transfer rate at position $z$ in the bed and time $t$, and $k_{G}$ is the solvent-side film mass transfer coefficient. In Eq. (2), Cg* is related to the concentration of lanolin in the liquid, $C_{L}$, through a Henry-type equilibrium constant, as is usually done in high pressure studies. Then:

$C_{g}^{*}=K C_{L}$

Note that $C_{L}$ decreases with increasing $z$, because of lanolin dissolution in the solvent occurs for increasing values of z. Using the following relationship:

$V_{L}=V \varepsilon_{L}$

the gas and liquid holdups, $\varepsilon$ and $\varepsilon_{\mathrm{L}}$ and the Henry constant, K, Eqs. (1) and (2), become:

$$
\begin{aligned}
& \varepsilon \frac{\partial C_{g}}{\partial t}+u \frac{\partial C_{g}}{\partial z}=K k_{G} a\left(C_{L}-\frac{C_{g}}{K}\right) \\
& -\frac{\partial C_{L}}{\partial t}=\frac{K k_{G} a}{\varepsilon_{L}}\left(C_{L}-\frac{C_{g}}{K}\right)
\end{aligned}
$$

Fig. 1 Separex 200 unit process flow diagram. P1, MiltonRoyal CO2 pump; P2, PulsaFeeder ethanol pump; HE1, $\mathrm{HE2}$, HE3, heat exchangers; BPR back-pressure control valve; $E$, Separex 200 extractor vessel; $\mathrm{S}$, Separex cyclone separator; $\mathrm{PI}$, pressure indicators; TIC temperature indicating controller; FC, flow controller

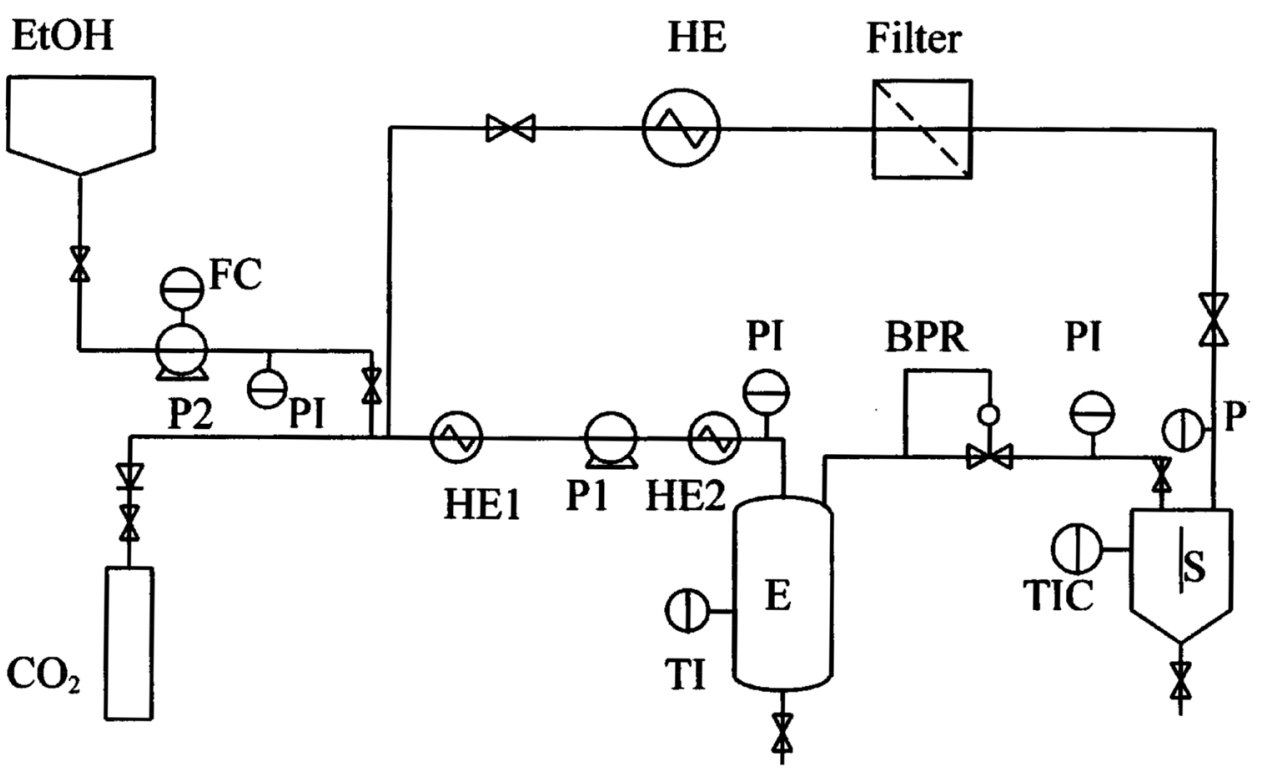

SN Applied Sciences A SPRINGer NATURE journal 
Table 2 Properties of extractor and wool used [4]

\begin{tabular}{ll}
\hline Extractor vessel & \\
\hline Shape & Cylindrical \\
Material & Stainless steel AISI $316 \mathrm{~L}$ \\
Inside dimensions & $145 \mathrm{~mm} \times 30 \mathrm{~mm}(\mathrm{H} \times \mathrm{D})$ \\
Volume & $100 \mathrm{~cm}^{3}$ \\
Cross section & $706.8 \mathrm{~mm}^{2}$ \\
\hline Wool fibers & \\
\hline Wool load in extractor & $13 \mathrm{~g}$ \\
Wool composition & $60-65 \%$ wool proper, 10-15\% wax and proteins, $10 \%$ soluble stains \\
& $(\mathrm{salts}), 1-20 \%$ soil and vegetable matter \\
Fiber geometry & Cylindrical \\
Average fiber length (approx.) & $15 \mathrm{~cm}$ \\
Initial fiber radius, $\mathrm{R}$ & $8.3 \mu \mathrm{m}$ \\
Initial fiber radius, $\mathrm{r}_{0}$ & $10 \mu \mathrm{m}$ \\
Lanolin content & $20 \%$ wt \\
Types of lanolin & Two lanolin fractions (external and internal) \\
Lanolin melting point & $38-44$ C C \\
\hline
\end{tabular}

where $\varepsilon_{\mathrm{L}}$ is the liquid holdup taken as an average during a run. If the bed is initially loaded with new wool, and the inlet solvent is lanolin-free, the initial and boundary conditions for Eqs. (5) and (6), are:

$C_{g}(t, z=0)=C_{g}(t=0, z)=0$

$C_{L}(t=0, z)=C_{L 0}$

where $C_{\mathrm{L} 0}$ is the initial concentration of lanolin covering the fibers. As will be noted, $C_{L 0}$ equals the pure lanolin density.

\subsection{Initial state of the bed: lanoline breakthrough at bed exit}

An expression for $C_{L}(t)$ is available if we consider the molecular diffusion of lanolin over a quiet liquid layer in contact with the solvent and a fluid-side mass transfer coefficient, $D$ and $k_{G}$, respectively [14]. It is not difficult to show [15] that the expression of $C_{L}(t)$ at bed inlet, $z=0$, is:

$C_{L}=C_{L O} e^{\frac{R k_{G} K}{D}\left(1-\sqrt{1+\frac{r_{0}^{2} k_{G} a k t}{R^{2}(1-\varepsilon)}}\right)}$
Equation (9) indicates that $\mathrm{C}_{\mathrm{L} 0}$ drops rapidly to zero. In Eq. (9), D is the molecular diffusivity of lanolin in the liquid, $R$ is the final radius of the wool fiber, and $r_{0}$ is the initial radius. $\mathrm{k}_{\mathrm{G}}$ is the solvent-side mass transfer coefficient. The mass transfer group, $\mathrm{Bi}$, is a modified Biot number for mass transfer,

$\frac{R k_{G} K}{D}=B i$

Now, let us see what happens at the end of the bed. In our previous work, Fullana et al. [16] showed in Fig. 13 of their article the value of the extraction yield in the fluid $\mathrm{C}_{\mathrm{g}}$ versus time during solute breakthrough for three different velocities of extraction. The response of an extraction bed consists in a time delay, called here $n$ later, of constant concentration, in which $\mathrm{C}_{\mathrm{g}}$ decreases more or less rapidly depending on the solvent flow rate. After a step input pulse of solvent at bed inlet, $z=0$, the shape of the breakthrough curve corresponds to an inverse step at $z=z_{\mathrm{T}}$. The shape of the breakthrough curve can be found from Eq. (9) and can be fitted to an empirical function, as we discuss next.

By performing the operations under the square root of Eq. (9), it is found that, 
$C_{L}=C_{L 0} e^{B i(1-\sqrt{1+A t})}$

where, the parameter $\mathrm{A}$ is,

$A=\frac{r_{0}^{2}}{R^{2}} \frac{k_{G} a K}{1-\varepsilon}$

After simplifying the exponent of Eq. (11), the following expression in terms of $\mathrm{Bi}$, is obtained,

$C_{L}=C_{L 0} e^{B i} e^{-B i \sqrt{1+A t}}=c^{\prime} e^{-\alpha \sqrt{n+t}}$

where $\mathrm{c}$ is a constant, $\alpha=B i / \sqrt{n}$, and $\mathrm{n}=1 / \mathrm{A}$. Equation (13) has the form of the cumulative probability of a Weibull distribution function [15]. This has a form of the type,

$C_{L}=c^{\prime} e^{-\alpha(n+t)^{b}}$

In this equation, $\mathrm{n}+\mathrm{t}$ is the total time, and $\mathrm{b}=1 / 2$. The graphical form of $C_{L}$ given by Eq. (14) is the response to a unit step input after time $\mathrm{n}+\mathrm{t}$. Therefore, knowing the values of $b$ and $a$, the Weibull expression (14) gives the breakthrough curve, that is, the decreasing sigmoid curve at bed exit after the step pulse at the inlet. Knowing the exit breakthrough curve, the extraction yield of lanolin as a function of time can be obtained during an extraction run, as we show next.

The fraction of solute extracted at time $t$ in a run, $X(t)$, in terms of $\mathrm{Cg}\left(\mathrm{t}, \mathrm{z}_{\mathrm{T}}\right)$ at bed exit, $\mathrm{C}_{\mathrm{g}}\left(\mathrm{t}, \mathrm{z}=\mathrm{z}_{\mathrm{T}}\right)$, is obtained with the following expression,

$X(t)=\frac{\int_{0}^{t} C_{g}\left(t, z_{T}\right) d t}{\int_{0}^{\infty} C_{g}\left(t, z_{T}\right) d t}$

In this equation, the function $C_{g}$ is the concentration of solute in the extraction solvent at bed exit and time t. Let us call B the denominator of Eq. (15). B represents the total solute extracted in a run; hence, it is a constant independent of time. Differentiating Eq. (15) with respect to time, we find that $C_{g}\left(t, z_{T}\right)$ is related to $d X / d t$, as

$C_{g}\left(t, z_{T}\right)=B \frac{d X}{d t}$

Now, if $C_{g}\left(t, z_{T}\right)$ is approximated with the Weibull function (Eq. (14)), the extraction yield, $X(t)$, is obtained by integration of $\mathrm{dX} / \mathrm{dt}$ from Eq. (16), as

$X(t)=c \int_{0}^{t} e^{-\alpha(t+n)^{b}} d t$ where $\mathrm{c}$ is a constant. We then come to the following important conclusion: when the breakthrough curve is approximated with a Weibull function (with known $a$ and b), the fraction extracted as a function of time, $X(t)$, can be calculated by the integral of the Weibull function as suggested by Eq. (17). To simplify the adjustment of $c, a, b$ and $n$, an analytical expression of the integral of Eq. (17) is found by means of the following expression,

$X(x)=\frac{c}{b \omega} \int_{0}^{x} x^{\frac{1}{b}-1} e^{-x} d x=\frac{c}{b \omega} \gamma\left(\frac{1}{b}, x\right)$

where $\alpha=\omega^{b}$ and $x^{1 / b}=\omega t$, and $\gamma\left(\frac{1}{b}, x\right)$ is the incomplete gamma function with $1 / \mathrm{b}$ as argument, which might not to be integer. This function can be approximated by a Taylor power series using the expression reported by Press et al. [17], as

$\gamma(m, x)=e^{-x} x^{m} \sum_{k=0}^{\infty} \frac{x^{k}}{(m+k)(m+k-1) \ldots m}$

The latter is very suitable for $\mathrm{x}<<a$ and for arguments not necessarily integers nor positive. In this case, if time is expressed in hours, with enough terms of the series from Eq. (19) an approximation with little error can be found. Thus, applying Eq. (19) to Eq. (18) and replacing original variables, following expression can be easily found [15],

$X(t)=c e^{-\left(\frac{c}{b} \Gamma\left(\frac{1}{b}\right)(t-n)\right)^{b}}(t-n) \sum_{k=0}^{\infty} \frac{\frac{1}{b}\left(\left(\frac{c}{b} \Gamma\left(\frac{1}{b}\right)(t-n)\right)^{b}\right)^{k}}{\left(\frac{1}{b}+k\right)\left(\frac{1}{b}+k-1\right) \ldots \frac{1}{b}}$

where $\alpha=\left(\frac{c}{b} \Gamma\left(\frac{1}{b}\right)\right)^{b}$ as the limit of the function at infinity must be equal to one. In our calculations, the analytical expression of Eq. (20) for the integral of the Weibull has been employed to obtain augmented data of the lanolin extraction curves. The results of the statistical analysis are given in paragraph 5.1 given below.

\subsection{Artificial neural networks}

Neural networks are models inspired by the structure and function of biological neurons. Like those, they can recognize patterns, structure disordered data and in general learn from observation. See Gupta [18] for a modern review publication on Deep Learning in chemical engineering. A neural network is able to learn by changing the connecting weights between neurons during the learning stage. After having learned, the knowledge is somehow stored in the weights. 
In the present work, an ANN system is used to predict the extraction yield of lanolin from wool from a number of learning experimental data sets. The variables that affect the extraction rate are the essential input data. Here we used those given by Eychenne et al. [4] and were summarized in Table 1. In the present case, the input neuron layer would contain 5 units. This means that the extraction yield depends on the following 5 variables: pressure, temperature, solvent flowrate, wool compression, and time.

The effect of time is very important in the network architecture and how it works. A typical extraction run is dynamic in nature, because the extraction yield in a run depends on time [4]. Let us see how we could construct the net. There is an efficient ANN to use when we have a time-varying output. The best network method for a dynamic process is to use a recurrent network, where time is taken into account. Bulsari and Palosaari [14] show why recurrent networks are best employed in their adsorption case with solute breakthrough. We implemented this type of network in our extraction problem, because desorption is somehow the reverse process of adsorption, where solute breakthrough at the end of the column is desired.

\subsection{Neural networks tools available}

In our early work on neural computing [16], we employed our own programs for the design and training of the neural network. We used the backpropagation algorithm to calculate the weights during the learning stage. Modern authors, however, prefer to use optimization algorithms more efficient than backpropagation. In this work, we have used the Levenberg-Marquardt (LM) algorithm [14]. The general purpose neural network available in the Matlab toolbox is feedforwardnet, that uses the LM algorithm for the weights. In our work, other Matlab methods for timedependent outputs, based on recurrent networks, were employed, such as NARXNET.

\subsection{Recurrent networks and dynamic data}

A feedforward network has no notion of order in time, and the only input it considers is the current example to which it has been exposed in the learning stage. Feedforward networks do not remember their recent past. Recurrent networks, on the other hand, take as their input not only the current input learning data that they see, but also what they have perceived previously in time. In dynamic networks, the output depends not only on the current input to the network, but also on the current or previous inputs, outputs, or previous states of the network. This allows the possibility to use neural networks for such applications where time-dependent or historical data are produced, either with randomly time-varying inputs or with ordered inputs increasing or decreasing with time. There are many examples of this; here we cite only two of them. One example is the randomly varying stock market values over a certain period of time, in which the stock value is to be predicted. Another example is the temporal evolution of a physical variable that takes place at increasing values, as in our case.

\section{Data treatment for neural networks}

We used NARXNET in the present work. This consists in a feedforward network that accepts two types of inputs, each multiplied by a so-called delay. The first type of input is an external input, these are values of previous times on which the output depends. The second type of input is a feedback input, that corresponds to a value or values of previous times of the same output. So that the output at time $t$ depends on such previous times. Mathematically, this dependence can be expressed as,

$$
\begin{gathered}
Y(t)= \\
f\left[Y(t-1), Y(t-2), \ldots, Y\left(t-n_{Y}\right),\right. \\
\left.U(t-1), U(t-2), \ldots, U\left(t-n_{U}\right)\right]
\end{gathered}
$$

where $Y$ is the output variable and the input variable of previous inputs, and $U$ is the external variable. Then the delays applied to each input are a vector of integers ( 1 , 2, 3....).

As far as training is concerned, it is very important how data are entered to the network, because in our case there are several extraction curves corresponding to different operation states. If the NARXNET net has to understand correctly, both the external input and the feedback is a cell array, where for each cell all operation states (for $\mathrm{U}$ ) or extracted fractions (for $\mathrm{Y}$ ) of a given time are contained. In such a way that the values at $t=0$ will correspond to the first cell, in the next cell there will be the values after 2 time steps, etc. Each cell of the external input will be formed by a matrix whose rows will consist of a different variable $P$, $T, Q$, or $\rho_{B}$, and each column will correspond to a state of operation of a different curve. Therefore, that matrix will have 4 rows, and 10 columns at most. As regards to the feedback input, this will be a row vector corresponding to the extracted fraction for each different state of operation for the time of the corresponding cell, therefore it will have at most 10 columns.

As regards to the network architecture, we have used in principle the default values for NARXNET. But it will be revised, as commented later in the Results and Discussion, paragraph 4. 


\subsection{Training data set and test data set}

In order to validate the network, only 9 of the 10 states of operation are used for the training phase, that is, saving only one state (the test data set) for checking the validity of the network. The selection of the test data set is not made at random because there is a limited number of states of operation, and it is our aim that the network correctly learns the effect of each variable. For robustness, we have used for training all the combinations in which only one variable changes while the other three remain constant, so the effect of this variable can be learned properly. For the testing, we have selected a state of operation in which the evolution of its variables can be seen from other groups of data. For this reason, the state reserved for the test is: $120 \mathrm{bar}, 80^{\circ} \mathrm{C}, 5 \mathrm{~kg} / \mathrm{h}$ and $127 \mathrm{~kg} / \mathrm{m} 3$.

Once the network structure has been chosen, in order to make a prediction after the network has been trained it will be necessary to introduce the desired state of operation as an external input, together with the first extraction value that is taken as a feedback to calculate the next one. In all cases the initial value is $X_{i}^{\mathrm{t}=0}=0$. Then, the network works in closed-loop to predict the rest of the extracted fractions for the extraction curve at successive times, always holding constant the same external state of operation.

Figure 2 illustrates schematically how the network works.

\subsection{Training parameters and prediction error}

The settings for the training parameters used by Matlab are shown on Table 3.

The index of performance of a NN used here is the absolute average of relative deviations, defined statistically [18] as,

$A A R D \%=\frac{1}{N} \sum_{i=1}^{N} \frac{\left|X_{i}^{\exp }-X_{i}^{N N}\right|}{X_{i}^{\exp }} 100$

where $\mathrm{N}$ is the number of data in a curve, that is, the number of time steps evaluated,

$X_{i}^{e x p}$ is the extracted fraction regressed with the Weibull function, and $X_{i}^{N N}$ is the fraction predicted by the network. As will be discussed in the Results and Discussion, for all the curves included in the training set and in the test set, their AARD\% was calculated. In all cases, if this value is less

Table 3 Matlab training parameter values

\begin{tabular}{ll}
\hline Training parameter & Value \\
\hline Learning rate & 0.001 \\
Maximum iterations & Infinite \\
Goal (maximum mean squared error) & $10^{-20}$ \\
Maximum time & $4 \mathrm{~min}$ \\
Minimum gradient & $10^{-20}$ \\
Maximum number of validations & Infinite \\
\hline
\end{tabular}

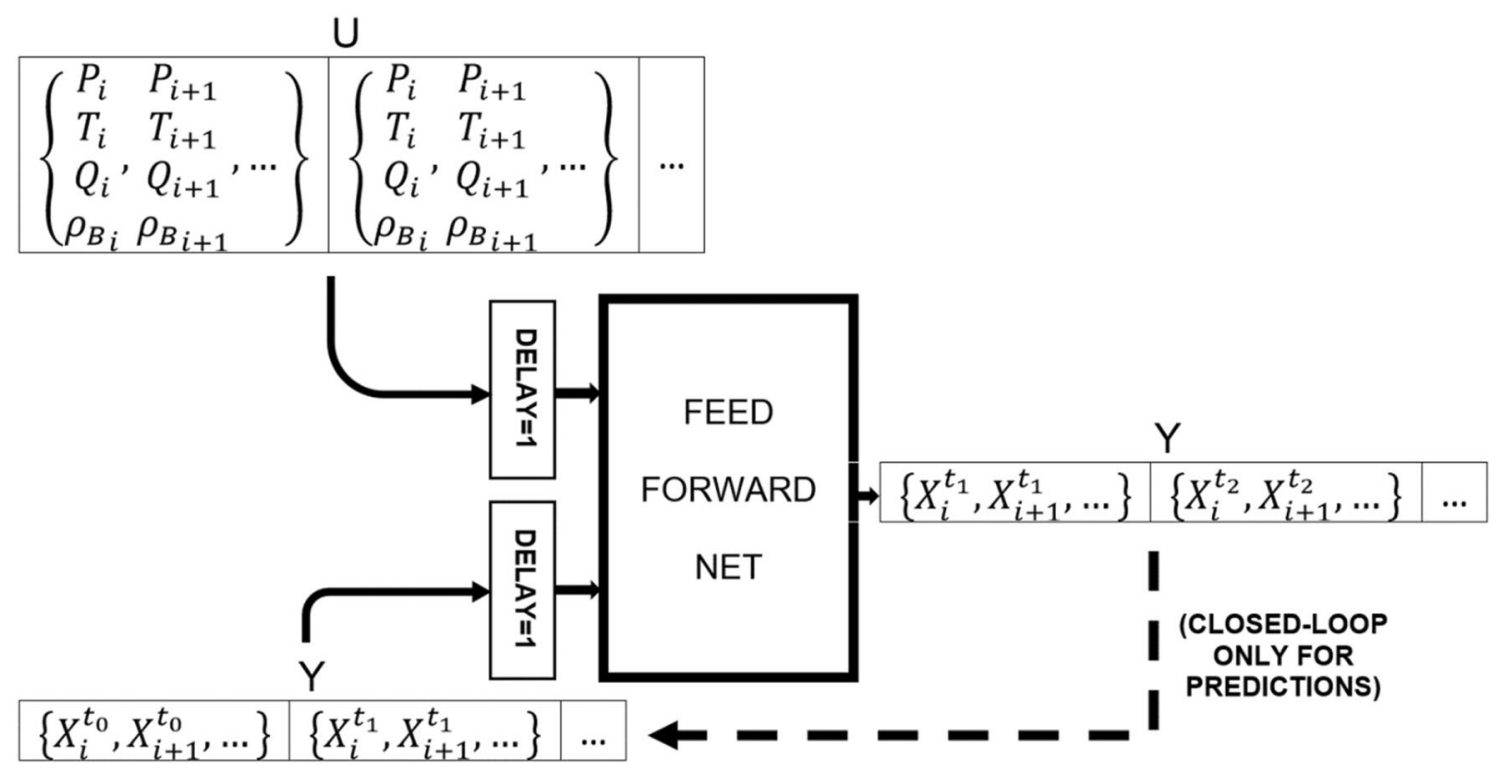

Fig. 2 Input, output and delays in a recurrent neural network. For predictions, not for training, the net works in closed-loop entering the previous output as the feedback input of the network. $i, i+1$,
..., correspond to a different data set (or extracted fraction curve), and $\mathrm{t}_{0}, \mathrm{t}_{1}, \ldots$, are the different time steps 
than the tolerance, then the network is accepted, otherwise the training is repeated. The first step is the selection of the architecture of the network. As will be discussed later in the results, with 1 or 2 neurons in the hidden layer the result with the test is very good, but the training error increases. Conversely, a large number of neurons has the opposite effect. Clearly, there are an optimum number of neurons in the hidden layer.

\section{Results and discussion}

Before we present the results on the neural net computing, we examine first the results of the statistical analysis given under the paragraph 3.1

\subsection{Results of statistical study}

Because of the difficulties of working at high pressure, the measurements in an extraction run were not replicated. Before proceeding to the neuronal computing, two statistical tests were done, so we fitted the time response of the extraction runs (see Fig. 3) using expression (14) as regression equation, as suggested by the shape of the curves $X(t)$, and the theory. Both coefficients obtained from regression and their t-student statistical test results are summarized in the tables that follow.

In Table 4 we give the parameters obtained by fitting the data points with the integral of the Weibull function calculated analytically, Eq. (18). In the table, the $p$-value from $t$-test of fitted parameters is provided. $n$ is the time delay, Eq. (17). At 120 bar, $80^{\circ} \mathrm{C}$ and $4 \mathrm{~kg} / \mathrm{h}$ an evident error of experimental data consisting of an unusual initial delay has been overcome by setting a $n$ value different from the theoretical one $\left(n^{\prime}\right)$. $c^{\prime \prime}$ is the solubility value obtained from Weibull distribution, while sol. is the solubility extracted from Eychenne et al. [5].

The results suggest that the exponent of the time variable (b) from Eq. (14) evolves from a value of 0.5 (equal to the theoretical one) to a value between 1 and 2 in most of cases at the extractor's outlet. It is a reasonable behavior since both values are close and $b$ increases as expected because of the profile of the curve. Solubility values obtained from the regressed equation $\left(c^{\prime \prime}\right)$ agree very well too those found experimentally by Eychenne et al. [5] for most of the operating conditions; besides, the first two regressions at $3 \mathrm{~kg} / \mathrm{h}$, are probably due to the lack of extracted fraction values at higher extraction times.

The $t$-test applied to regression coefficients shown in Table 4 demonstrates the significance of these coefficients in the regression, as for most cases the $p$-value is lower than 0.05 and, therefore, they are significant factors of
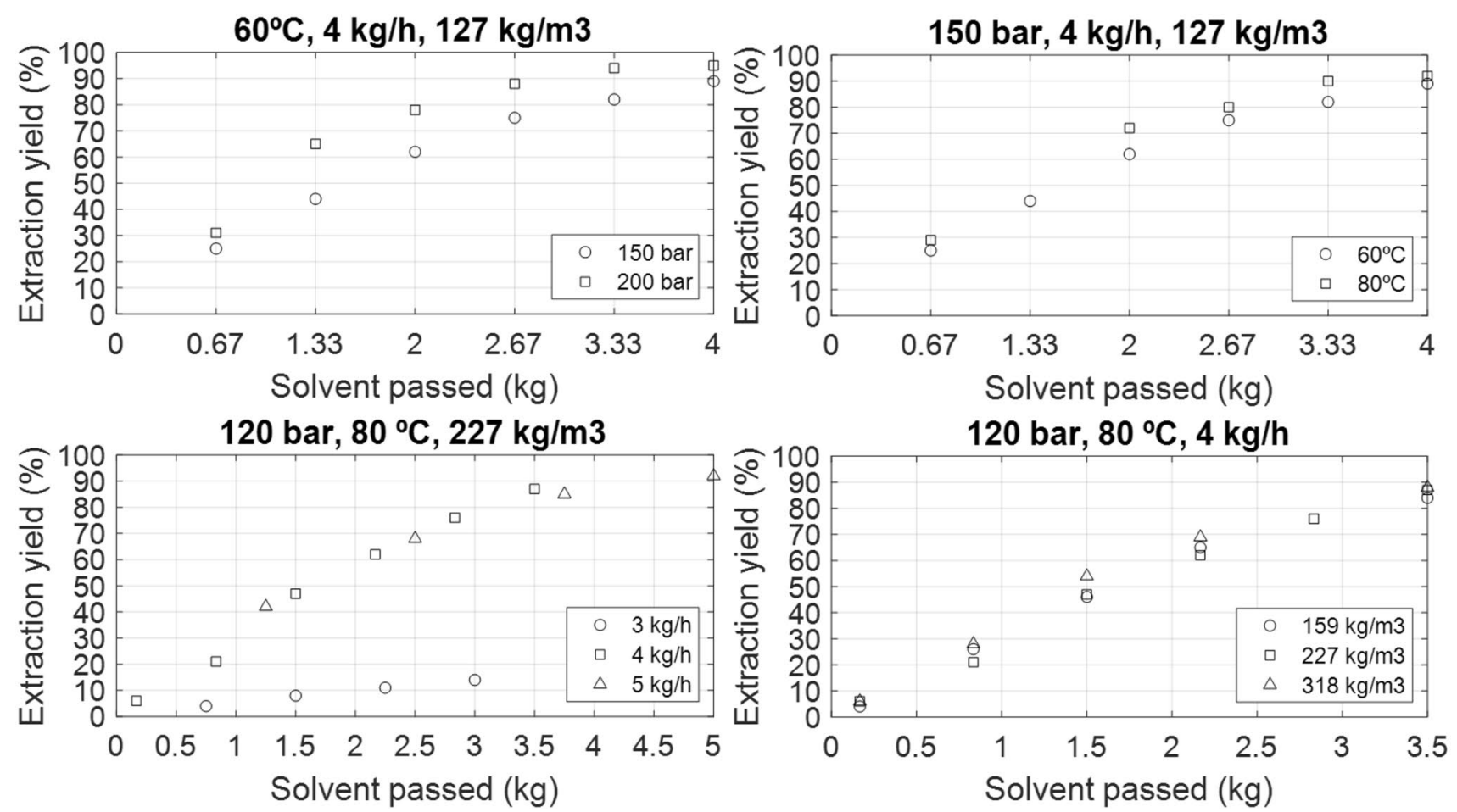

Fig. 3 Experimental data from Figs. 5, 6b, 8b, $9 \mathrm{~b}$ and 10 of Eychenne et al. [4]. Data available at $120 \mathrm{bar}, 80^{\circ} \mathrm{C}, 3 \mathrm{~kg} / \mathrm{h}$ and $127 \mathrm{~kg} / \mathrm{m}^{3} \mathrm{has} \mathrm{not}$ been represented as it matches with the exact same values of those at same conditions and $4 \mathrm{~kg} / \mathrm{h}$ 
Table 4 Parameters of fitting Weibull's cumulative distribution function integral to experimental data points

\begin{tabular}{|c|c|c|c|c|c|c|c|c|c|c|}
\hline P (bar) & $\mathrm{T}\left({ }^{\circ} \mathrm{C}\right)$ & $\mathrm{Q}(\mathrm{kg} / \mathrm{h})$ & $\rho_{B}\left(\mathrm{~kg} / \mathrm{m}^{3}\right)$ & $c(p$ value $)$ & a ( $p$ value) $(i)$ & $\mathrm{b}$ ( $p$ value) & $\mathrm{n}(i i) \mathrm{h}$ & $\mathrm{n}^{\prime}(i i i) \mathrm{h}$ & $c^{\prime \prime}(i v) \mathrm{kg} / \mathrm{m}^{3}$ & sol. $\mathrm{kg} / \mathrm{m}^{3}$ \\
\hline 120 & 80 & 3 & 127 & $0.183(0.103)$ & $0.560(0.13)$ & $1.023(0.516)$ & 0.0111 & & 0.057 & 0.33 \\
\hline 120 & 80 & 3 & 227 & $0.174(0.090)$ & $0.510(0.15)$ & $1.216(0.524)$ & 0.0057 & & 0.054 & 0.33 \\
\hline 120 & 80 & 4 & 159 & $1.430(2 \mathrm{E}-4)$ & 1.524 & $1.738(0.003)$ & 0.1415 & 0.0065 & 0.33 & 0.33 \\
\hline 120 & 80 & 4 & 227 & $1.227(5 \mathrm{E}-5)$ & 1.271 & $2.735(0.018)$ & 0.1305 & 0.0043 & 0.29 & 0.33 \\
\hline 120 & 80 & 4 & 318 & $1.599(6 \mathrm{E}-4)$ & 1.837 & $1.713(0.010)$ & 0.1346 & 0.0028 & 0.37 & 0.33 \\
\hline 120 & 80 & 5 & 127 & $2.194(0.129)$ & 2.279 & $1.097(0.162)$ & 0.1350 & 0.0092 & 0.41 & 0.33 \\
\hline 120 & 80 & 5 & 227 & $1.983(0.002)$ & 2.175 & $1.276(0.004)$ & 0.0051 & & 0.37 & 0.33 \\
\hline 150 & 60 & 4 & 127 & $1.669(2 \mathrm{E}-5)$ & 1.772 & $1.340(2 \mathrm{E}-4)$ & 0.0155 & & 0.73 & 0.74 \\
\hline 150 & 80 & 4 & 127 & $2.114(0.001)$ & 2.338 & $1.255(0.003)$ & 0.0115 & & 0.68 & 0.69 \\
\hline 200 & 60 & 4 & 127 & $2.556(8 \mathrm{E}-4)$ & 3.073 & 1.309 (0.004) & 0.0176 & & 1.26 & 1.24 \\
\hline
\end{tabular}

(i) For the first two operating conditions $(\mathrm{Q}=3 \mathrm{~kg} / \mathrm{h})$ a has been fitted along with $c$ and $b$ because of the lack of data at higher extraction times. In all the other cases $a$ has been calculated fixing the value of the function limit to infinity at 1 through the equation $a=(\Gamma(1 / b) c / b)^{b}$ after finding $c$ and $b$

(ii) $n=z_{T} \varepsilon / u=Z_{T} \pi R_{B}^{2} \varepsilon \rho_{s} / Q$, see terms in the list of symbols section

(iii) Note that $n-n$ ' always results in the approximate constant 0.13 value, namely, the experimental error done when time was recorded (iv) $c^{\prime \prime}=\mathrm{cm}_{\mathrm{L}} \rho_{\mathrm{s}} / \mathrm{Q}$ as $C_{g}\left(Z_{T}, t\right)=(d X / d t) m_{L} \rho_{s} / Q$, where $m_{L}$ is the mass of lanoline, $C_{g}\left(z_{T}, t\right)$ the concentration of lanolin in the solvent at the extractor outlet

the regression with a $95 \%$ confidence level. Only the first two runs at $3 \mathrm{~kg} / \mathrm{h}$ are out of this interval, likely because the available experimental values are those of the first linear slope of extraction; and at $120 \mathrm{bar}, 80^{\circ} \mathrm{C}, 5 \mathrm{~kg} / \mathrm{h}$ and $127 \mathrm{~kg} / \mathrm{m}^{3}$, probably because the error on the experimental data (actually first value was excluded).

The goodness of fit was also assessed through Fisher's $F$ statistical test, and for a further characterization of the regression, statistical parameters of the associated Weibull distribution were also found. These results are summarized on Table 5.

On one hand, goodness of fit parameters are shown, i. e. the degrees of freedom (df), the R-squared $\left(R^{2}\right)$, the adjusted $R$-squared $\left(\operatorname{Adj} . R^{2}\right)$, the root mean squared error (RMSE), and the $p$-value (pVal) obtained from the $F$-test of the regression. On the other hand, the associated Weibull distribution parameters are given, i.e. the mean $(\mu)$, the variance $\left(\sigma^{2}\right)$, the median $(\mathrm{Me})$ and the mode $(\mathrm{Mo})$ of the distribution.

As for the $F$-test results of the overall regression given on Table 5, besides the low RMSE values found, two parameters highlight. On one hand, most of adjusted $R^{2}$ values are higher than 0.99 , even for operating conditions with 3 and 4 degrees of freedom, suggesting a very good fitting of the model to the experimental data. On the other hand, in all cases the $p$-values are lower than 0.05 , proving the goodness of the fit at the $95 \%$ confidence level.

The statistical parameters of the associated Weibull distribution of each fitting are also shown on Table 5. Those parameters describe how the extracted fractions and lanolin concentrations in the solvent phase are distributed over time. The mean values clearly decrease with increasing pressure, temperature, flow rate and packing density in most of the cases. As will be seen later, this trend agrees with the results obtained from neural network predictions, since the increase of those operating conditions leads to predicted extraction curves with higher initial slope and an earlier end of extraction. As far as the variance is concerned, this shows the same relation with increasing operating conditions as the mean does, since when initial extraction slope is higher, extraction data is more concentrated around the mean extraction time. The median indicates the time halfway to the end of the extraction. Despite the median gives significant information about the total duration of a run, note that it is not the time where the extracted fraction is 0.5 . It is always higher than the mean value, indicating that more than half of the lanolin present in the bed is extracted during the first half. Finally, mode is an interesting parameter as it indicates the time with the maximum reaction rate at the extractor outlet $z_{\mathrm{T}}$. This corresponds to the inflection point of the lanolin breakthrough curve. The low values of mode suggest that the extraction front quickly reaches the extractor outlet, deflecting in a slow extraction onwards until it is completed.

In conclusion, the Weibull statistical distribution explains accurately the behavior of experimental data, so it is suitable for data augmentation. The values obtained will conform a semi-empirical training set for the design and implementation of the neural network. 
Table 5 Results of statistical analysis

\begin{tabular}{|c|c|c|c|c|c|c|c|c|c|c|c|c|}
\hline \multirow[t]{2}{*}{$\mathrm{P}$ (bar) } & \multirow[t]{2}{*}{$\mathrm{T}\left({ }^{\circ} \mathrm{C}\right)$} & \multirow[t]{2}{*}{$\mathrm{Q}(\mathrm{kg} / \mathrm{h})$} & \multirow[t]{2}{*}{$\rho_{B}\left(\mathrm{~kg} / \mathrm{m}^{3)}\right.$} & \multicolumn{5}{|c|}{ Goodness of fit statistics } & \multicolumn{4}{|c|}{ Weibull parameters } \\
\hline & & & & $d f$ & $R^{2}$ & Adj. $R^{2}$ & RMSE & pVal & $\mu(h)$ & $\sigma^{2}\left(h^{2}\right)$ & $\mathrm{Me}$ & Mo \\
\hline 120 & 80 & 3 & 127 & 1 & 0.999 & 0.997 & $2.2 \mathrm{E}-03$ & 0.014 & 1.747 & 2.917 & 1.244 & 0.054 \\
\hline 120 & 80 & 3 & 227 & 1 & 0.999 & 0.997 & $2.3 \mathrm{E}-03$ & 0.014 & 1.632 & 1.819 & 1.294 & 0.426 \\
\hline 120 & 80 & 4 & 127 & 3 & 0.999 & 0.999 & $8.8 \mathrm{E}-03$ & $1.3 \mathrm{E}-6$ & 0.703 & $(*)$ & 1.141 & 1.145 \\
\hline 120 & 80 & 4 & 159 & 3 & 0.999 & 0.998 & $1.3 \mathrm{E}-02$ & $6.2 \mathrm{E}-6$ & 0.699 & 0.192 & 0.777 & 0.621 \\
\hline 120 & 80 & 4 & 227 & 4 & 0.995 & 0.994 & $2.5 \mathrm{E}-02$ & $1.5 \mathrm{E}-6$ & 0.815 & 0.121 & 0.932 & 0.921 \\
\hline 120 & 80 & 4 & 318 & 3 & 0.997 & 0.996 & $2.0 \mathrm{E}-02$ & $1.9 \mathrm{E}-5$ & 0.625 & 0.160 & 0.701 & 0.555 \\
\hline 120 & 80 & 5 & 127 & 1 & 0.988 & 0.980 & $2.4 \mathrm{E}-02$ & 0.019 & 0.456 & 0.191 & 0.473 & 0.187 \\
\hline 120 & 80 & 5 & 227 & 2 & 0.999 & 0.998 & 8.7E-03 & $6.8 \mathrm{E}-5$ & 0.504 & 0.159 & 0.413 & 0.169 \\
\hline 150 & 60 & 4 & 127 & 4 & 0.998 & 0.998 & $1.1 \mathrm{E}-02$ & $3.3 \mathrm{E}-8$ & 0.599 & 0.204 & 0.512 & 0.250 \\
\hline 150 & 80 & 4 & 127 & 3 & 0.997 & 0.996 & $1.7 \mathrm{E}-02$ & $5.1 \mathrm{E}-6$ & 0.473 & 0.144 & 0.391 & 0.154 \\
\hline 200 & 60 & 4 & 127 & 4 & 0.991 & 0.988 & 2.7E-02 & $5.8 \mathrm{E}-7$ & 0.391 & 0.091 & 0.338 & 0.158 \\
\hline
\end{tabular}

(*) Incorrect value found. The fitting at these operating conditions was not considered for the neural network training because of the error in the experimental data

\subsection{Data augmentation}

The present work is based on the experimental data taken from the crude data reported in Fig. 3. Only temperatures above $50^{\circ} \mathrm{C}$ and pressures above 100 bar have been considered. On Table 1 the different states of operation in terms of $\mathrm{P}, \mathrm{T}, \mathrm{Q}$ and $\rho_{\mathrm{B}}$, are given. For every state, measurements of the extracted fraction were done at only 6 times (sometimes only 4), within about $1 \mathrm{~h}$ for each run. As will be noted, for a given run the number of data points is very scarce. Therefore, a method for data augmentation is necessary. As discussed in paragraph 3.1, the integral of the Weibull function can be used to regress the observed extraction values. To this purpose, an analytical integral for Eq. (19) was used. In practice, the parameters $a$ and $b$, for each run were obtained.

In order to assess that data augmentation and that the fitted extraction curves are correct, the densities of solvent and other lanolin properties are necessary; these were taken from our previous work.

\subsection{Fitting the experimental extraction data}

The fitting procedure used in data augmentation depends on the parameters $c, a, b$ and $n$. The time $n$ represents the time shift from which the $X(t)$ starts to have a positive value, so that it corresponds to the point $(n, 0)$. In order to calculate $n$, we apply its definition, that is, $n$ is the time taken by the solvent to reach the end of the bed. So $\mathrm{n}$ can be calculated simply as,

$n=\frac{z_{T} \varepsilon}{u}=\frac{z_{T} \pi R_{B}^{2} \varepsilon \rho_{S}}{Q}$
Finally, when the parameters $c, a, b$ and $n$ for all the runs of Fig. 3 are known, it is possible to calculate the value of $C_{g}\left(t, z_{T}\right)$ for the experimental runs. A sample of this calculation is shown on Fig. 4. It is clear that the Weibull function fits the experimental data points very well.

\subsection{Designing the network}

The method implemented in this work consists of an iterative training of the nonlinear autoregressive neural network until maximum AARD\% goal both in training and test predictions is satisfied (see Fig. 5). Most common training algorithms act as local optimization routines in order to adjust the weights with the goal to minimize the error between predicted values and experimental targets. Initial weight population is stochastic, namely takes a different value at each new run, which may lead to a different local optimum depending on the initial weights basin. In this case, iterating training is used as a means to achieve a multistart global optimization.

As noted in paragraph 4. (Data treatment for neural networks), there is a substantial difference in the prediction error in terms of the AARD\% for the training data and for the test data when the number of neurons in the hidden layer is changed. Recall that the ranges of the variables $P, T$, $Q, \rho_{B}$ are those of Table 1. Our first result is that the default value applied in NARXNET (10 neurons) is unnecessarily large. Instead, we found that a reduced number of 2 to 5 neurons are sufficient to obtain a small AARD\%. In Table 6 we show the results of the errors as a function of neurons in the hidden layer.

Now focusing on the diverse training algorithm available in literature, a comparison between their suitability in 

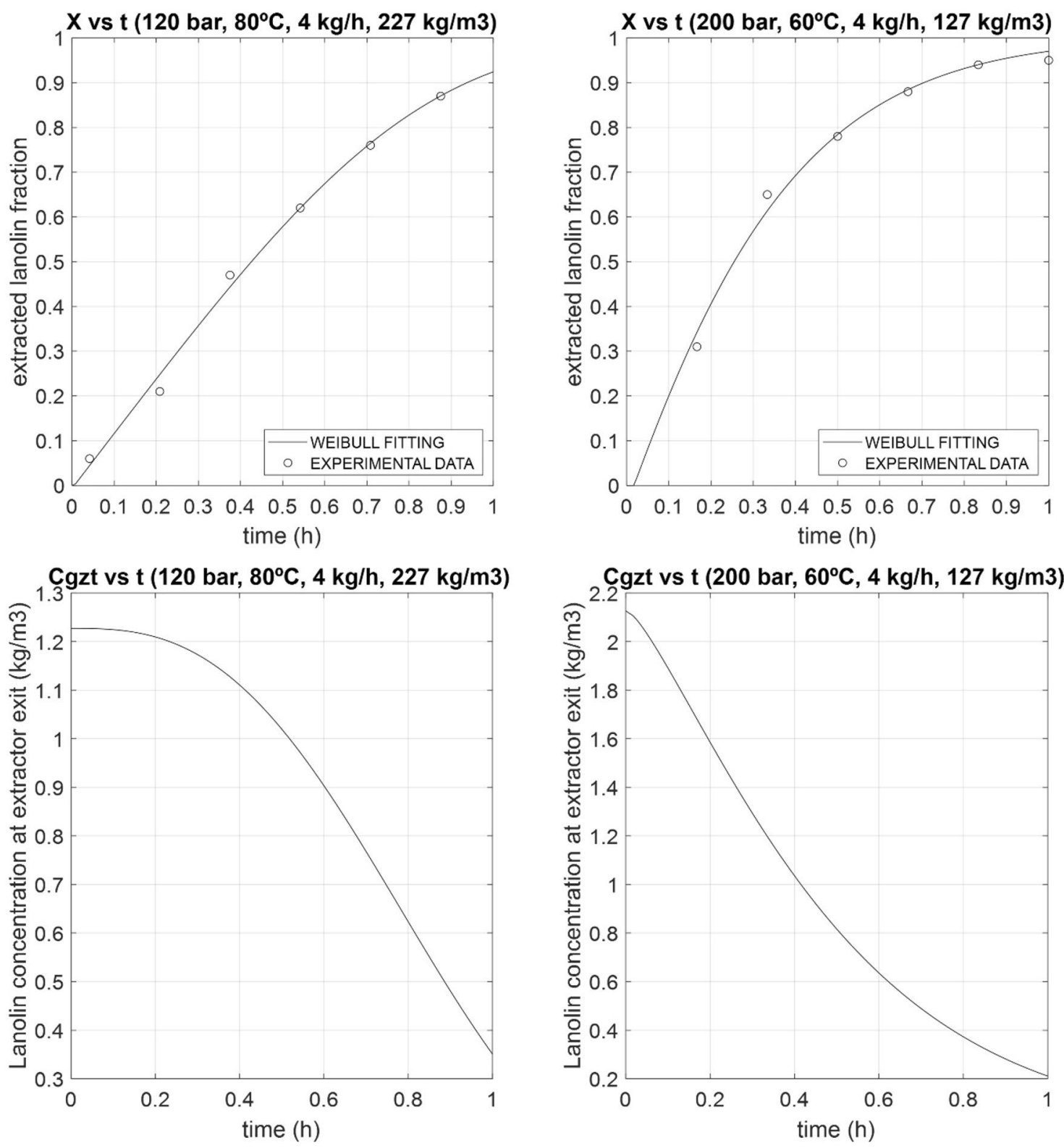

Fig. 4 Top curves are the fractions of lanolin extracted, $X(t)$, fitted with the Weibull function after data augmentation (continuous lines), and compared with the measured extraction data. Bottom

terms of performance, convergence and speed has been carried out. The results are shown in Table 7.

The iterative training method presented in Fig. 5 has been run with diverse training algorithms and the results are shown in Table 7. However, since the number of training iterations is random, in Table 7 only results of the best training for each algorithm is considered. Therefore, training times must be seen as an indicator of the overall time that the method presented in this paper might last, as the mean time until finding the best training run is closely related to those presented in Table 7.

curves are the lanolin breakthrough at end of bed calculated by differentiation of the top curves

As it can be seen, there is a clear difference in terms of convergence between first three methods exposed in Table 3 and the other ones. Gradient descent, resilient back propagation, conjugate gradient and one step secant always reach maximum time or epochs restriction obtaining a worse AARD\% of training data. This poor efficiency is in contrast with the low AARD\% value obtained after scarce time with the Levenberg-Marquardt, Bayesian Regularization, and BFGS Quasi-Newton algorithms. Despite these three algorithms show similar convergence, the neural network obtained with 


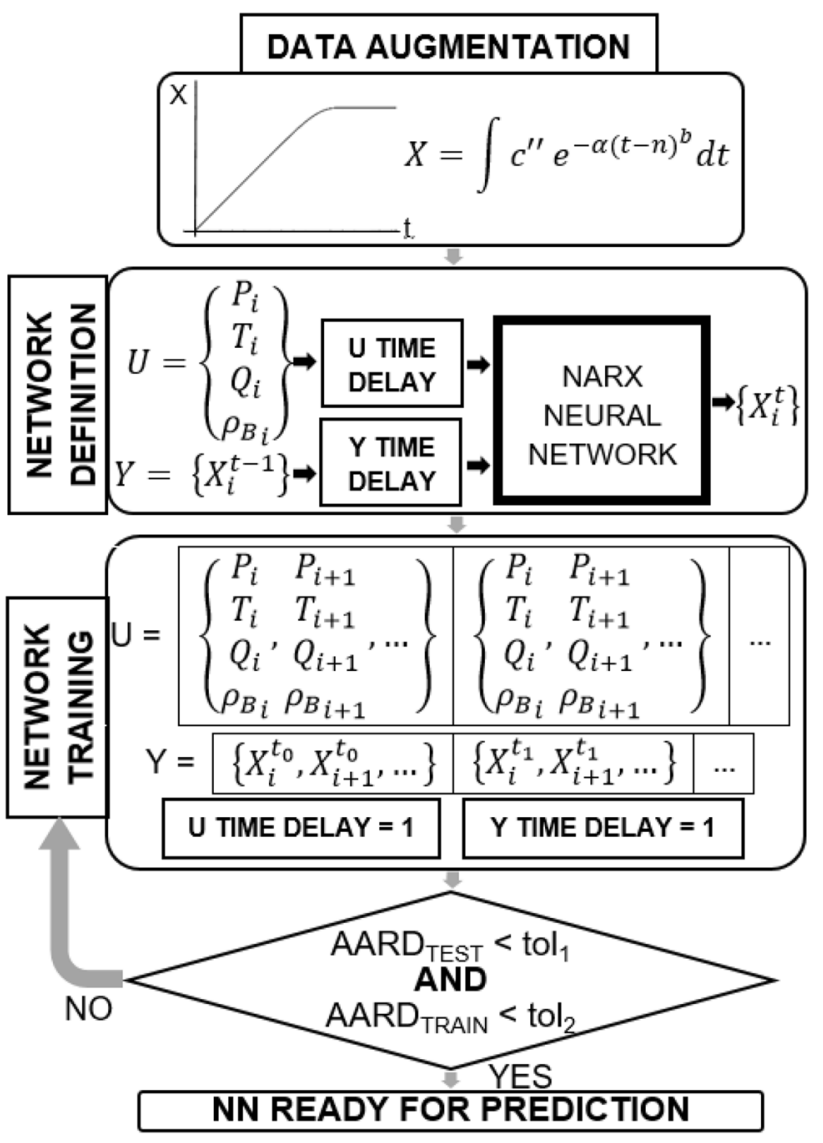

Fig. 5 Final hybrid nonlinear autoregressive neural networkWeibull statistical model scheme

Table 6 Error as AARD\% for each training set as a function of nodes in hidden layer ${ }^{\mathrm{a}, \mathrm{b}}$

\begin{tabular}{lll}
\hline Number of neurons & Average training error ${ }^{c}$ & $\begin{array}{l}\text { Error in } \\
\text { test data } \\
\text { set }\end{array}$ \\
\hline 2 & $5.55 \%$ & $0.47 \%$ \\
3 & $4.15 \%$ & $0.42 \%$ \\
4 & $3.13 \%$ & $2.76 \%$ \\
5 & $2.63 \%$ & $3.68 \%$ \\
\hline
\end{tabular}

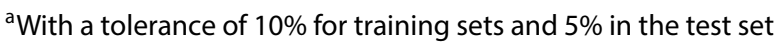

${ }^{\mathrm{b}}$ Training sets include the variables $\mathrm{P}, \mathrm{T}, \mathrm{Q}$ and $\rho_{\mathrm{B}}$ of Table 1

${ }^{\mathrm{C}}$ Average AARD\% of 9 training sets

the Levenberg-Marquardt training algorithm is selected to predict final results, because it reaches the lowest AARD\% value in only $30 \mathrm{~s}$.

As regards to other network architectures, after exploring other possibilities such as not regressive feedforward nets, long-short term memory networks, and autoregressive not exogenous networks among others, all of them where discarded because of input data requirements
Table 7 Performance of different training algorithms

\begin{tabular}{lrlc}
\hline Training algorithm & Epochs & Time (s) & AARD\% \\
\hline Levenberg-Marquardt & 6634 & 30 & 4.15 \\
Bayesian regularization & 1109 & 5 & 5.64 \\
BFGS quasi-Newton & 9008 & 35 & 5.14 \\
Gradient descent & 100,000 & 218 & 89.35 \\
Resilient back-propagation & 100,000 & 234 & 20.81 \\
Conjugate gradient & 88,609 & 280 & 12.25 \\
One step secant & 83,693 & 280 & 30.86 \\
\hline
\end{tabular}

and time forecasting suitability. Moreover, the problem raised in this paper regarding extraction prediction has not received much attention in literature, making comparison with other prediction algorithms difficult and, on the other hand, proving the novelty of the method proposed.

We see that the smallest error in the test set is obtained with 3 neurons and using Levenberg Marquardt training algorithm. See Fig. 6.

\subsection{Results on the individual effects of the variables.}

The merit of the neural networks developed in this work is to provide a tool that predicts the effects of the variables on the extraction process. That function is,

$X=f\left(P, T, Q, \rho_{B}, t\right)$

As to the effect of time, an initial condition has been imposed, i.e., the extracted fraction at $t=0$ is $X=0$. From then on, time is taken into account in closed-loop for as many time steps as needed to predict the curve $X(t)$ up to the desired final time. With these conditions, the network is a function of time, and the effects of the variables can be compared with the experimental results. The results are shown on Fig. 7, where the separate effects of the main variables $\left(P, T, Q\right.$ and $\left.\rho_{B}\right)$ are compared with the experimental data on extracted fraction.

Figure 7 shows that the network prediction is generally quite satisfactory. It is observed that for a run time of $1 \mathrm{~h}$, the extracted fraction $X(t)$ increases when any one of the variables increases: pressure, temperature, flow rate, or packing density. Assuming that this trend continues even though experimental data are not available, the results shown in Fig. 8 would be the expected results.

It is seen on Fig. 8 that in all cases the prediction of the neural network follows a trend that is consistent with the results of Fig. 7. For the calculations shown on Fig. 8, the network has been used not only to predict when several state variables change relative to the experiments, but also 


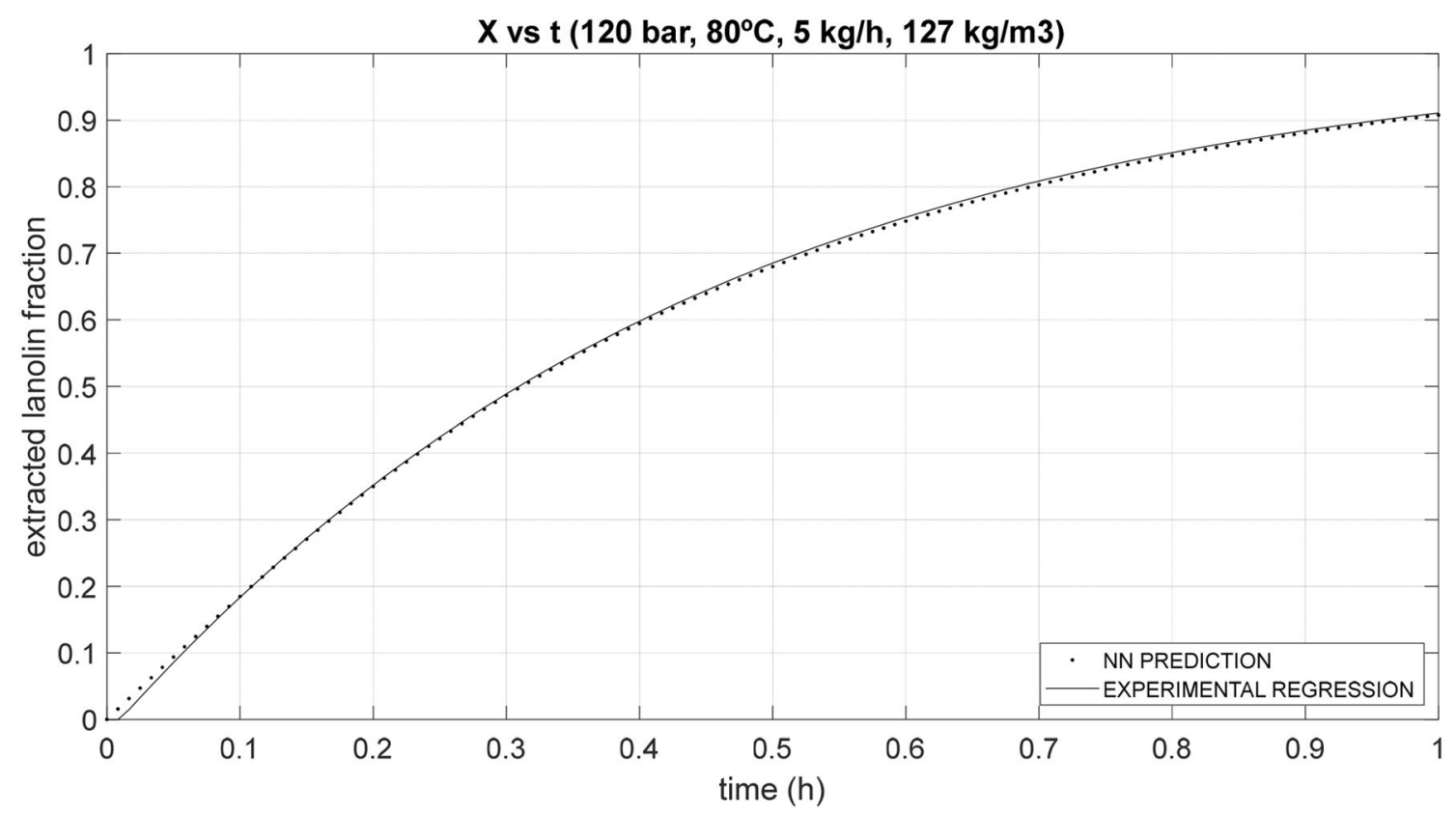

Fig. 6 Extracted fraction predicted with the test set using a trained neural network with 3 neurons in the hidden layer
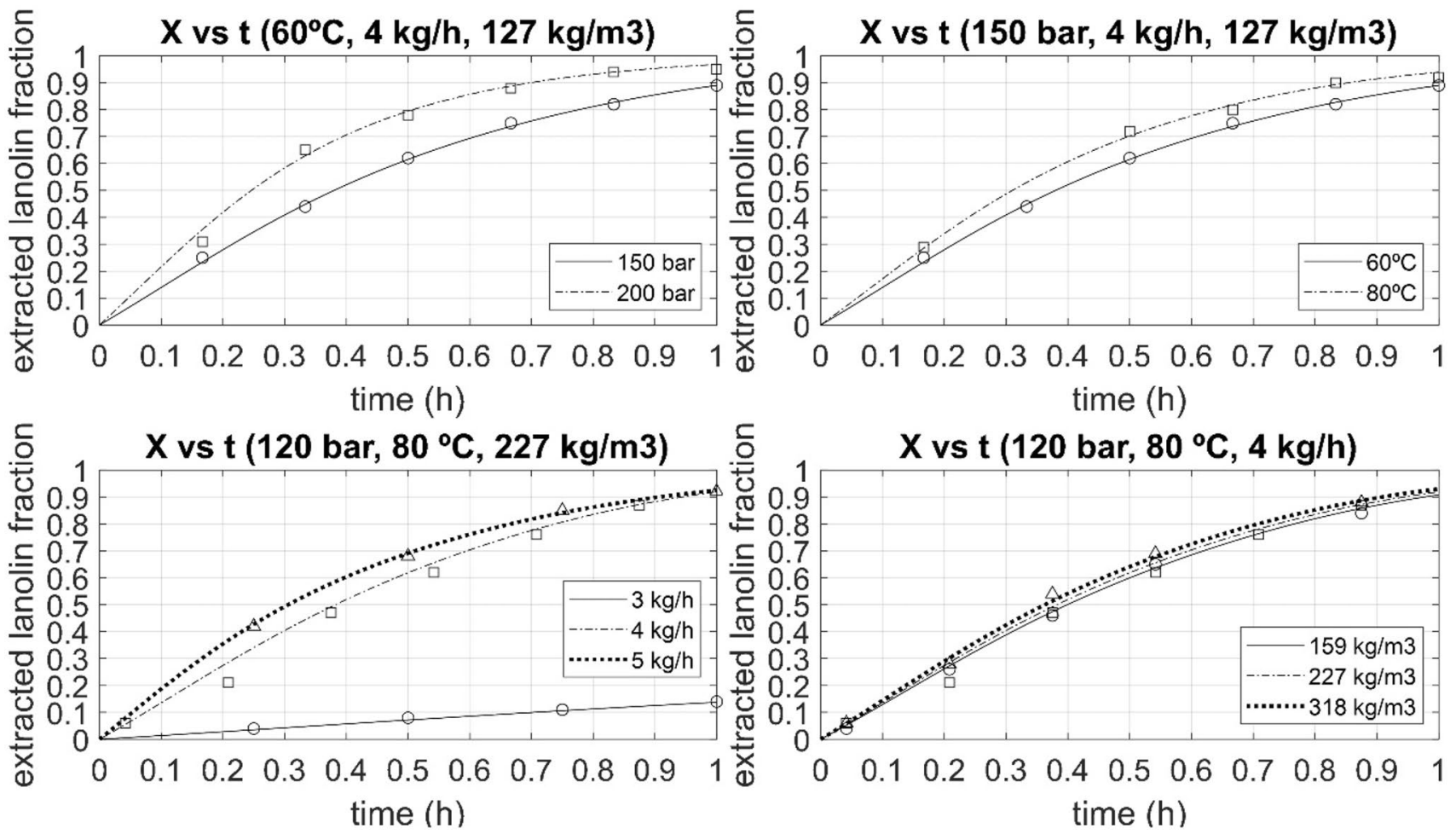

Fig. 7 Effect of the pressure, temperature, flow rate and packing density on the extracted fraction. Data points are the measurements [4]. Continuous lines are the neural network predictions 
to predict values where only one variable change relative to the experiments. The conclusion is that the neural network developed seems to predict reasonably well in quite different situations.

\subsection{Optimization problem formulation using genetic algorithm}

Our last finding allows using the tool developed to find optimum operating conditions for the extraction process. There are two types of optimization problem formulations to be considered.

The first optimization problem considered can be stated as follows. For a total extraction time of $1 \mathrm{~h}$, find the best set of variables that maximize the extraction yield. To solve this problem we have applied the global optimization algorithm called GA (genetic algorithm) available in Matlab. Since once defined, the network is able to calculate the predictions quite fast, the solution to the problem proceeds very rapidly to the global optimum with a low computational cost, despite $G A$ is known to be quite slow for cases where the objective function involves many calculations. The result of this optimization problem is readily obtained, the maximum yield is for the following set of variables: $200 \mathrm{bar}, 80^{\circ} \mathrm{C}, 4,55 \mathrm{~kg} / \mathrm{h}, 318 \mathrm{~kg} / \mathrm{m}^{3}$. That maximum yield is obtained in $0.70 \mathrm{~h}$ (42 $\mathrm{min})$.
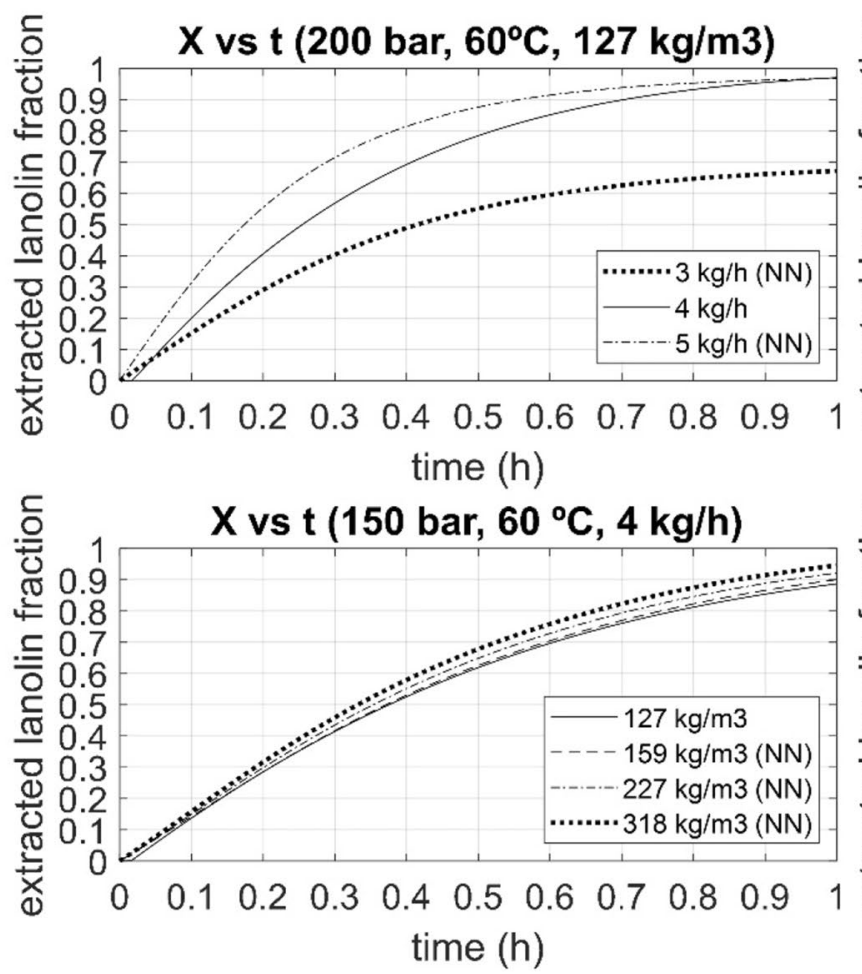

A second optimization problem is stated as follows. Find the minimum operating conditions to obtain at least a $90 \%$ extraction yield. We also used the $G A$ algorithm for this problem. Depending on the selection of the objective function, we could add a larger weight to a certain variables to emphasize a particular aspect of the process. For example, we can be interested in economy or in simplicity. For instance, no weight can be added, so that as a result the most important variable is solvent flow rate Q. We know, however, that the cost of increasing flow rate affects economy unfavorably. By contrast, if the variables are standardized depending on the limits of each variable, an optimum is obtained for all variables changed proportionally.

The results of both types of optimization are shown in the extraction curves of Fig. 9 where the left one is the result of the first optimization, and the other two curves at right show 2 possible optima of the second optimization possibility, first without weights added and finally with standardized data. It can be seen that those are the expected choices by inspecting the responses in Fig. 8, and the effects of flow rate on $X(t)$ shown in Fig. 7 .
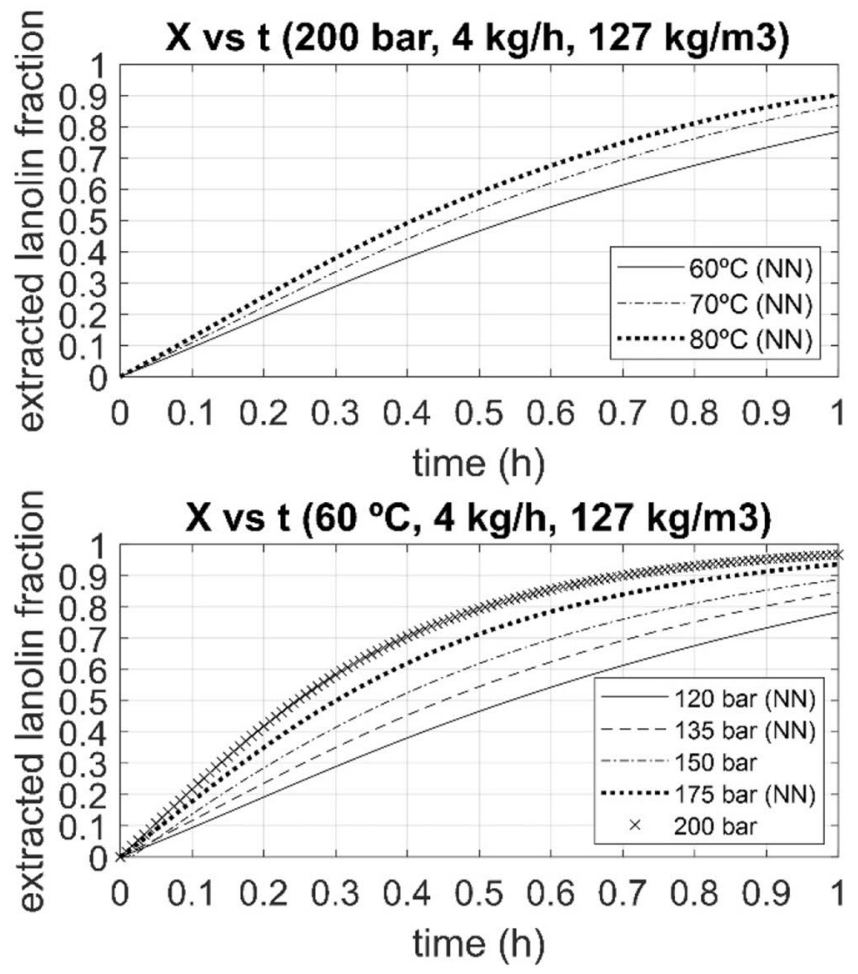

Fig. 8 Calculated effects of pressure, temperature, flow rate and packing density on the extracted fraction curves when experimental data are not available 
$\mathbf{X}$ vs $\mathbf{t}$

(200 bar, $80^{\circ} \mathrm{C}, 4,556 \mathrm{~kg} / \mathrm{h}, 318 \mathrm{~kg} / \mathrm{m} 3$ )

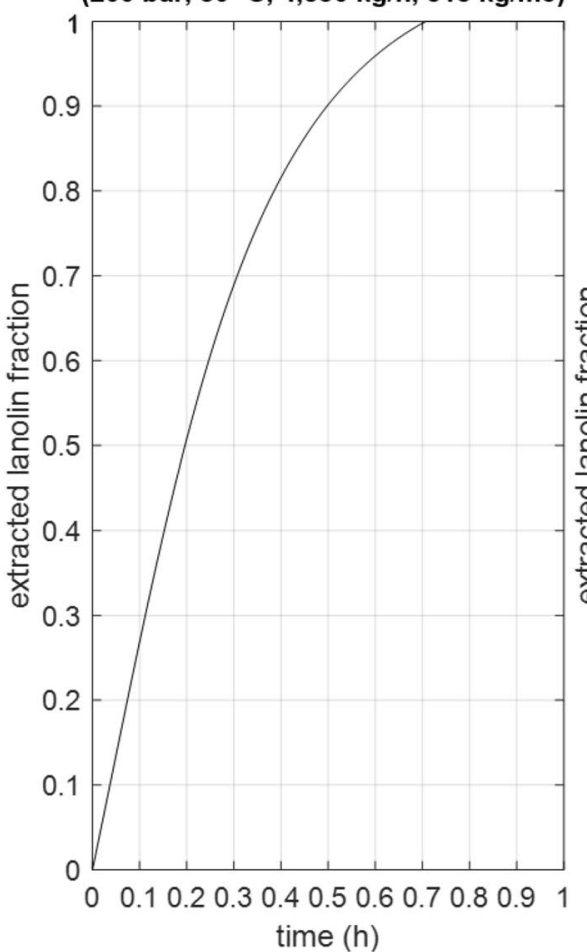

$\mathrm{X}$ vs $\mathrm{t}$

(120 bar, $\left.60^{\circ} \mathrm{C}, 4,87 \mathrm{~kg} / \mathrm{h}, 127 \mathrm{~kg} / \mathrm{m} 3\right)\left(150,4 \mathrm{bar}, 60,46{ }^{\circ} \mathrm{C}, 3,88 \mathrm{~kg} / \mathrm{h}, 141,2 \mathrm{~kg} / \mathrm{m} 3\right)$

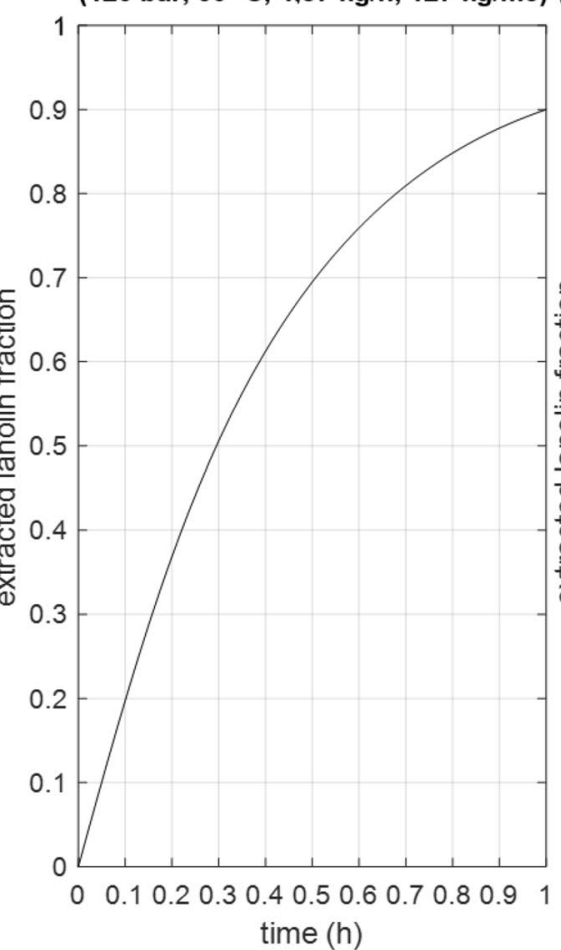

$\mathrm{X}$ vs $\mathrm{t}$

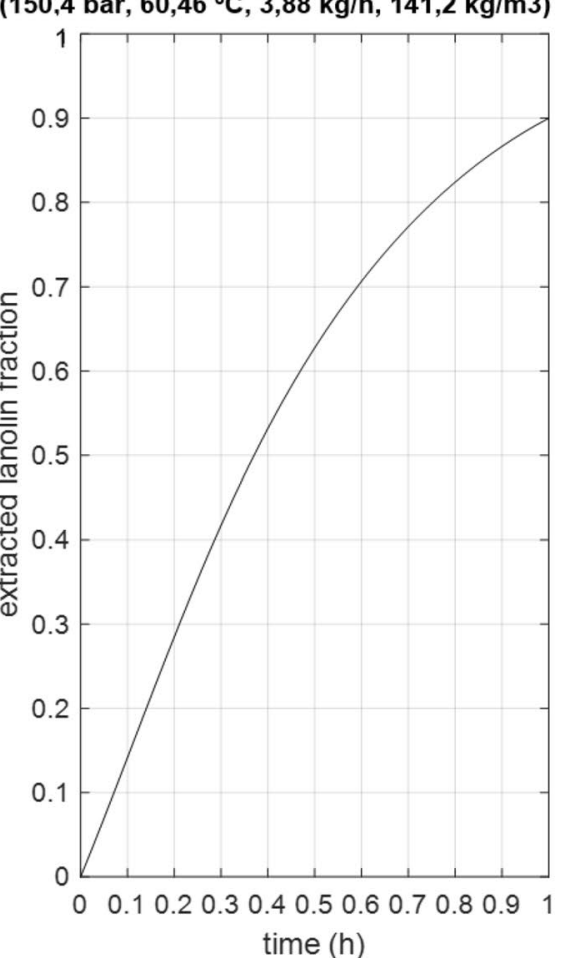

Fig. 9 First curve at left: extracted fraction curve for the optimum operating conditions ( $200 \mathrm{bar}, 80^{\circ} \mathrm{C}, 4,56 \mathrm{~kg} / \mathrm{h}$ and $318 \mathrm{~kg} / \mathrm{m}^{3}$ ) to obtain the maximum extraction yield in $1 \mathrm{~h}$. 2Other two curves at right: extracted fraction curve for the optimum operating condi-

\section{Conclusions}

In this work, we have used neural network computing for modeling the behavior of the near-critical extraction of lanolin from raw wool, as a function of the variables that affect the extraction yield. These variables are: pressure, temperature, mass flow rate, packing density, and time. A recurrent neural network designed is capable to predict the extracted fraction for any set of variables, within the scope of the experiments available. Our reference experiments were those previously published by our research group.

Once more, it has been shown that it is possible to design a neural computing model that has many applications in SCF extraction, without the need to develop and solve a complex physical model of the extraction process, and without a knowledge of the laws that govern the mass transfer rate within the extraction vessel.

The potential of this network has also been discussed, showing interesting applications, as it allows, among others, to develop studies to optimize the operating variables of the extraction process. A powerful global optimization tions to obtain at least $90 \%$ of lanolin extracted in $1 \mathrm{~h}$. Two possible solutions are shown; left: $120 \mathrm{bar}, 60^{\circ} \mathrm{C}, 4.87 \mathrm{~kg} / \mathrm{h}$ and $127 \mathrm{~kg} / \mathrm{m}^{3}$; right: $150.4 \mathrm{bar}, 60.46^{\circ} \mathrm{C}, 3.88 \mathrm{~kg} / \mathrm{h}$ and $141.2 \mathrm{~kg} / \mathrm{m}^{3}$

algorithm, such as genetic algorithm, may be used with a low computing time cost, because once the network is trained, it works like a simple function with basic arithmetic operations. Moreover, it offers the possibility of applying weights to the variables so the desired variable is enhanced.

Another development of this work has been to employ a statistical function that allows to model the lanolin breakthrough from a packed bed of wool from which lanolin is extracted. The function used is the Weibull cumulative probability distribution function. The integral of the Weibull function allows to regress the rather scarce extraction data and to produce a sufficient data augmentation to use in the neural algorithms. The use of the Weibull function is dictated by a physical model of extraction available to us from previous work.

\section{Compliance with ethical standards}

Conflict of interest The authors declare that they have no conflict of interest. 


\section{References}

1. Cygnarowicz-Provost M, King JW, Marmer WM, Magidman $P$ (1994) Extraction of woolgrease with supercritical carbon dioxide. J Am Oil Chem Soc 71:222-225

2. Kuo BS, Kim JC, Jeon JH, Bae HK (1992) Desorption of wool grease from greasy wool with supercritical carbon dioxide. Hwahak Konghak 30:491-498

3. Jones FW, Bateup DR, Dixon SR, Gray SR (1995) Solubility of wool wax in supercritical carbon dioxide. J Supercrit Fluids 10:100-111

4. Eychenne V, Sáiz S, Trabelsi F, Recasens F (2001) Near-critical solvent extraction of wool with modified carbon dioxide-experimental results. J Supercrit Fluids 21:23-31

5. Valverde A, Recasens $F$ (2019) Extraction of solid lanolin from raw wool with near-critical ethanol-modified $\mathrm{CO}_{2}$-a mass transfer model. J Supercrit Fluids 14:151-161

6. Bayona JM, Erra P, Moldovan Z, Domínguez C, Jover E, Recasens F, Larrayoz MA (2005) Method for obtaining lipid fractions from wool or lanolin using pressurized carbon dioxide, patent WO 2002100990A1, Spanish Patent and Trademark Office, Madrid, filed 16.07

7. Domínguez C, Jover E, Garde F, Bayona JM, Erra P (2003) Characterization of supercritical fluid extracts from raw wool by TLCFID and GC-MS. J Am Chem Oil Soc 80:717-724

8. Domínguez C, Erra P, Bayona JM (2010) Physico-chemical and dyieng properties of raw wool extracted by pressurized $\mathrm{CO}_{2} /$ modifiers. Text Res 80:651-659

9. López-Mesas M, Carrillo F, Gutiérrez MC, Crespi M (2007) Alternative methods for wool wax extraction from wool scouring wastes. Aceites y grasas 58:402-407
10. Puiggené J, Larrayoz MA, Recasens F (1997) Free liquid-tosupercritical fluid mass transfer in packed-beds. Chem Eng Sci 52:195-312

11. Bhat NV, McAvoy TJ (1989) Use of neural nets for dynamic modelling and control of chemical process systems. Comput Chem Eng 14:573-583

12. Blayo F, Verleysen M (1996) Les réseaux de neurones artificiels. Presses Universitaires de France, Paris

13. Bulsari $A B$ (ed) (1995) Neural networks for chemical engineers. Elsevier, Amsterdam

14. Bulsari AB, Palosaari S (1993) Application of neural networks for system identification of an adsorption column. Neural Comput Appl 1:160-165

15. Valverde $A, P h D$ thesis, to be published

16. Fullana M, Trabelsi F, Recasens F (2000) Use of neural net computing for statistical and kinetic modelling and simulation of supercritical fluid extractors. Chem Eng Sci 55:79-85

17. Press WH, Teukolsky SA, Vetterling WT, Flannery BP (1993) Numerical recipes in Fortran 77. Cambridge University Press, Cambridge

18. Gupta A (2018) Introduction to deep learning: part 1. Chem Eng Prog 114:22-29

Publisher's Note Springer Nature remains neutral with regard to jurisdictional claims in published maps and institutional affiliations. 